\title{
Attitude of the students regarding mandatory undergraduate research study in Physiotherapy
}

\author{
Ganvir, S. $^{1}$ \& Ganvir, S. $^{2}$
}

\begin{abstract}
Introduction: Research is one of the key distinguishing features of an academic institution. The nature of work and poor information retrieval habits even in developed settings makes it difficult to recruit already qualified health professionals into research. The alternative is to equip students so that at the time of qualifying they are conversant with various aspects of research methodology. Maharashtra University of Health Sciences has introduced an observational study to be conducted by final year physiotherapy students in the subject of Physiotherapy in Community Health. The purpose of this study is to identify the perception of the students regarding, undergraduate research Programme in terms of their interest, feasibility and, applicability. Our hypothesis was that the students are satisfied with the project allotted.
\end{abstract}

Methodology: This study was conducted as an observational study, using a self-administered questionnaire. The study was carried out between July 2008 - December 2009 on three separate occasions, for three different batches.

Result: The highest percentage rating was given to the point of inclusion of this kind of activity in the undergraduate curriculum, followed by theoretical introduction about the conducting of the same.

Conclusion: It was concluded that students had a positive attitude towards a mandatory project in their final year.

\section{Introduction}

Research is one of the key distinguishing features of an academic institution. The way an institution grooms its future researchers determines its long-term survival. The ability to do and communicate ones' research findings is so important that it is now an internationally recognized minimum competency for graduate of any medical school.

${ }^{1}$ Professor, College of Physiotherapy, Ahmednagar, Maharashtra University of Health Sciences, India.

${ }^{2}$ Professor \& Principal, College of Physiotherapy, Ahmednagar, Maharashtra University of Health Sciences, India.

Corresponding author:

Suvarna Ganvir

Professor, College of Physiotherapy,

Ahmednagar, Maharashtra University of Health Sciences, India.

Email: suvarna.ganvir@gmail.com
Over the years, other researchers in physical therapy have stated that research is important to

1. Validate physical therapy services

2. Provide information on the effectiveness of treatment

3. Improve patient care by making intelligent clinical decisions based on research findings

4. Provide answers to therapists' questions Michels, 1982; Payton, 1994; Domholdt, 1993).

The nature of the work and poor information retrieval habits even in developed settings make it difficult to recruit the already qualified health professionals into research (American Physical Therapy Association, 1999). The alternative is to equip students so that at the time of qualifying they are conversant with various aspects of research methodology. Training students should then lead to a bottomup change in research related practices over time (Michels, 1982).

The physical therapy profession, through accreditation standards for research (American 
Physical Therapy Association, 2014) and the American Physical Therapy Association (APTA) normative model of professional education (APTA, 1997) has addressed the importance of educating physical therapist students in the basic principles of research (Etminan et al., 1998; Morrissey, 1998; Ballin, 1980). Opinions range from having students critique published research, to writing research proposals but not actually carrying out projects, to adopting and assisting with a faculty research project, to actually completing an independent research project (Michels, 1982; Etminan et al., 1998; Tracy, 1992).

Ballin et al., (1980) studied a sample of California therapists and assessed the importance of research to them, as well as factors that impeded their involvement in research and the extent to which they used published research. Although they reported that $100 \%$ of the respondents agreed about the importance of research, identified barriers to participation in research was the inability to give up revenue-producing time, lack of administrative financial support, and unfamiliarity with research methods. The APTA (1996) Practice Profile Report revealed that only about $58 \%$ of graduates from both baccalaureate and post baccalaureate Programme indicated that they had sufficient knowledge of research methods and design to critically read and evaluate research reports published in scholarly journals. Likewise, a study of critical appraisal of research literature revealed that one half of the inexperienced physical therapy researchers indicated low levels of self-reported comfort with research.

The Maharashtra University of Health Sciences introduced an observational study to be conducted by final year physiotherapy students in the subject of Physiotherapy in Community Health. Students are required to carry out a survey under supervision of the allotted guide on the topics of Women's health, Geriatrics and Rehabilitation.
Students are assessed at the university practical examination in a project viva voce examination based on this study. The purpose of this study is to describe the perception of the students regarding this undergraduate research Programme in terms of their interest, feasibility, applicability.

\section{Method}

This study was conducted as an observational study using a self-administered questionnaire from July 2008 - December 2009 on three separate occasions for three different batches. Students who had successfully completed their projects and currently pursuing their internship Programme were included in the study. Privacy and confidentiality of the data were strictly maintained.

\section{Questionnaire}

The questionnaire consisted of 20 questions of which 18 were close ended questions and 2 were open ended questions. The questionnaire was prepared considering the whole process, expected outcomes and pre-tested prior to administration. Based on expert review, the final questionnaire was developed using a 5point Likert scale that ranged from 1 (strongly agree) to 5 (strongly disagree) to assess the students' degree of agreement with each statement. The final items were formulated to determine whether changes occurred with time.

\section{Data collection}

The questionnaire was administered to students after the successful completion of the project and a maximum time of 10 minutes were taken to complete the questionnaire.

\section{Results}

The questionnaire was completed by 55 students, of which 49 were female. $0.5 \%$ of the students were previously exposed to research which did not affect outcome of this study (Table 1).

\section{Table 1: Items of the questionnaire for students}

\begin{tabular}{lc}
\hline \multicolumn{1}{c}{ Item } & Response Mean (SD) \\
\hline It is necessary to have a mandatory project in final year & $4.7(0.6)$ \\
There should be fixed sample size & $4.1(0.7)$ \\
I had sufficient guidance \& support & $4.3(0.4)$ \\
It should be done in groups & $4.1(0.5)$ \\
There should be some theoretical introduction about the conduction of the project & $4.6(0.5)$ \\
There should be some recognition to the project in the form of certification or credit & $4.7(0.5)$ \\
hours in the transcript & $4.2(0.3)$ \\
This project has given an insight for the conduct of research & $4.2(0.4)$ \\
There should be separate time period to be specified for the data collection. & $4.3(0.4)$ \\
Overall it was helpful for me &
\end{tabular}




\section{Discussion}

The primary goal of the undergraduate research Programme is to introduce students to the concept of research and motivate them to conduct research in future on their own. This present study was conducted on undergraduate students, about their experience of the mandatory project to be conducted in the final year of physiotherapy. The question on the necessity of having this kind of activity is reflected by the positive attitude of students, and obtained the highest mean. This correlates well with the probability of conducting research on their own in future ( $\mathrm{rs}=0.47)$.

The second highest rating was for the opinion of giving some kind of recognition in the form of a certificate or mentioning the hours spent in the transcript. At present this project is not represented anywhere either in the mark list or in the transcript, although there is a definite mark allotted during the university practical examination. It is absolutely justifiable on the part of the students as they spend enough time money, and energy in conducting this research. Considering, conducting a research is a completely novel area for the undergraduate, students should be oriented collectively at the beginning of the session for the procedure to conduct the study. At present there are no guidelines available and once students are allocated to supervisors, it is their responsibility to start from beginning. Hence the students were of the opinion that there should be some fundamental lectures on conducting a project.

Students had varied opinions about the fixed sample size. Considering it to be an observational study, usually on commonly seen conditions, the authors are of the opinion that there should be fixed sample size or at least a predetermined range that should be common to all. At present the number of patients to be included in the study depends on various factors such as the condition at investigation, source of sample, availability of resources and etc.

A mixed response was reported on the opinion regarding whether the project should be done in groups or individually. At one end of the spectrum, the students gave preference to group work and at the other end they felt it should be done individually. The preference may depend on their experience with research projects or personal traits. In the personal opinion of the author, if it is done in groups it will save time on the part of the students since it is being done along with the routine schedule of their final year.

The usefulness of the project in near future received a mixed response. There can be various factors responsible for this kind of a response like supervisor's attitude, expectations from the students, the topic selected, and student's own interest in the project can affect this.

Open Ended Questions reflected the expectations of the students from supervisors that they should be more open towards the views of the students. Additionally, students expressed their concern about the money that needs to be spent and the reward later on.

A study by Veerapen (2010) also revealed that there was a positive perception of students about the teachers' attributes. It is further stated that the teachers should act as facilitators rather than information providers.

\section{Conclusion}

From the study it can be concluded that students have a positive attitude towards this mandatory research project in their final year physiotherapy Programme. However, at the same time they have some concerns which should be taken into consideration while formulating the guidelines of this Programme.

Future aspects: Staff members involved in this project also have their own perceptions regarding its implementation. As a next step, it is planned to explore the perceptions of teachers so that when both stakeholders are screened, it will be further easier to prepare guidelines.

\section{References}

American Physical Therapy Association (APTA) (2014) Commission on Accreditation in Physical Therapy Education, Evaluative Criteria for Accreditation of Education Programmes for the Preparation of Physical Therapists, APTA: Virginia, USA.

American Physical Therapy Association (1999) Goals of Clinical Research in Physical Therapy, APTA: Virginia, USA.

American Physical Therapy Association, (1997) Normative Model of Physical Therapist Professional Education, Version 97, APTA: Virginia, USA.

American Physical Therapy Association, (1996) Practice Profile Report, APTA: Virginia, USA. 
Ballin, A.J., Breslin, W.H., Wierenga, K.A.S. \& Shepard, K.F. (1980) Research in physical therapy: philosophy, barriers to involvement, and use among California physical therapists, Physical Therapy, 60, 7, pp.888-895.

Domholdt, E. (1993) Physical Therapy Research Principles and Applications, WB Saunders Co.: Philadelphia, $\mathrm{Pa}$.

Domholdt, E., Flaherty, J.L. \& Phillips, J.M. (1994) Critical appraisal of research literature by expert and inexperienced physical therapy researchers, Physical Therapy, 74, 9, pp. 853-860.

Etminan, M., Wright, J.M. \& Carleton, B.C. (1998) Evidence-based pharmacotherapy: review of basic concepts and applications in clinical practice, Annals of Pharmacotherapy 32, 11, pp. 1193-1200.
Michels E. (1982) Evaluation and research in physical therapy, Physical Therapy, 62, 6, pp.828834.

Morrissey, M.C., Kanda, L.T. \& Brewster, C.E. (1987) Development of a clinical physical therapy research Programme, Physical Therapy, 67, 7, pp.1110-1114.

Payton O.D., Sullivan, M.S. \& Laymon, M. (1994) Research, The Validation of Clinical Practice [3 ${ }^{\text {rd }}$ Ed.] FA Davis Co: Philadelphia, Pa.

Tracy, J.E. (1992) The role of research in the entrylevel physical therapy curriculum, Journal of Physical Therapy Education. 6, 1, pp. 28-32.

Veerapen, K. \& McAleer, S. (2010) Students' perception of the learning environment in a distributed medical Programme, Medical Education Online, 15,1, p. 5168. 